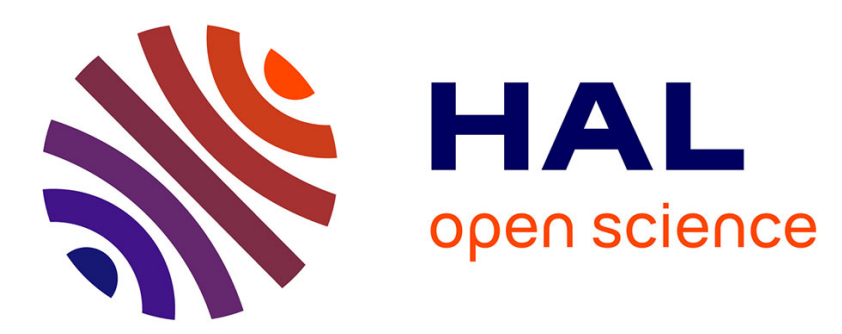

\title{
Evaluative conditioning of high-novelty stimuli does not seem to be based on an automatic form of associative learning
}

\author{
Jonathan Dedonder, Olivier Corneille, Vincent Yzerbyt, Toon Kuppens
}

\section{- To cite this version:}

Jonathan Dedonder, Olivier Corneille, Vincent Yzerbyt, Toon Kuppens. Evaluative conditioning of high-novelty stimuli does not seem to be based on an automatic form of associative learning. Journal of Experimental Social Psychology, 2010, 46 (6), pp.1118. 10.1016/j.jesp.2010.06.004 . hal-00864369

\section{HAL Id: hal-00864369 \\ https://hal.science/hal-00864369}

Submitted on 21 Sep 2013

HAL is a multi-disciplinary open access archive for the deposit and dissemination of scientific research documents, whether they are published or not. The documents may come from teaching and research institutions in France or abroad, or from public or private research centers.
L'archive ouverte pluridisciplinaire HAL, est destinée au dépôt et à la diffusion de documents scientifiques de niveau recherche, publiés ou non, émanant des établissements d'enseignement et de recherche français ou étrangers, des laboratoires publics ou privés. 


\section{Accepted Manuscript}

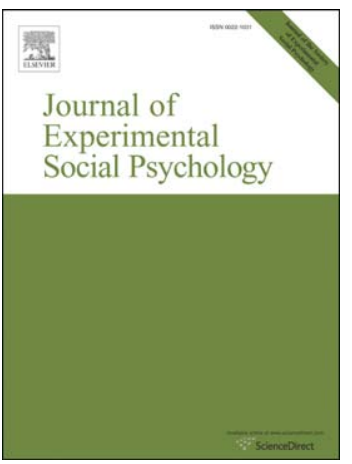

PII:

Reference:

doi: $10.1016 / j . j$ jesp.2010.06.004

Evaluative conditioning of high-novelty stimuli does not seem to be based on an automatic form of associative learning

Jonathan Dedonder, Olivier Corneille, Vincent Yzerbyt, Toon Kuppens

To appear in: Journal of Experimental Social Psychology

Received date: $\quad 30$ March 2010

Revised date: $\quad 4$ June 2010

Accepted date: 9 June 2010

Please cite this article as: Dedonder, J., Corneille, O., Yzerbyt, V. \& Kuppens, T., Evaluative conditioning of high-novelty stimuli does not seem to be based on an automatic form of associative learning, Journal of Experimental Social Psychology (2010), doi: 10.1016/j.jesp.2010.06.004

This is a PDF file of an unedited manuscript that has been accepted for publication. As a service to our customers we are providing this early version of the manuscript. The manuscript will undergo copyediting, typesetting, and review of the resulting proof before it is published in its final form. Please note that during the production process errors may be discovered which could affect the content, and all legal disclaimers that apply to the journal pertain. 
Running head: Evaluative conditioning for high-novelty stimuli

Evaluative conditioning of high-novelty stimuli does not seem to be based on an automatic form of associative learning.

Jonathan Dedonder

Olivier Corneille

Vincent Yzerbyt

$\&$

Toon Kuppens

Université catholique de Louvain, Louvain-la-Neuve, Belgium

Word count: 2247, including footnotes.

This work was supported by a Joint Research Grant (ARC 06/11-337) from the Communauté française de Belgique. Correspondence concerning this research may be addressed to Jonathan Dedonder. Université catholique de Louvain. IPSY. 10, Place du cardinal Mercier. B-1348 Louvain-la-Neuve, Belgium. Email: Jonathan.Dedonder@uclouvain.be 


\begin{abstract}
Evaluative conditioning (EC) refers to the change in valence of initially neutral stimuli (conditioned stimuli, or CSs) as a result of their pairing with positive or negative stimuli (unconditioned stimuli, or USs). EC is critical to dual-attitudes models as it is often presented as an evaluative effect that results from a purely automatic form of associative learning. Although evidence suggests that EC does not occur without contingency awareness, Ruys and Stapel (2009) recently argued that contingency awareness is unnecessary for high-novelty stimuli. Researchers may thus be tempted to conclude that EC rests on an automatic form of associative learning, at least for CSs associated with little prior evaluative knowledge. Taking issue with this claim, the present study reveals that EC of high-novelty stimuli is dependent on attentional resources. The role of contingency awareness in EC of high-novelty stimuli is also discussed.
\end{abstract}


Evaluative conditioning of high-novelty stimuli does not seem to be based on an automatic form of associative learning.

Evaluative conditioning (EC) is critical to dual-attitudes models as it is often portrayed as an evaluative effect that is based on a purely automatic form of associative learning (e.g., Gawronski \& Bodenhausen, 2006). However, evidence has now accumulated that questions this claim: EC has been shown to be sensitive to processing goals (Corneille, Pleyers, Yzerbyt \& Mussweiler, 2009; Gast \& Rothermund, 2010), attentional resources (Pleyers, Corneille, Luminet, \& Yzerbyt, 2007) and, more important, awareness for CS-US pairings (e.g., Dawson, Rissling, Schell \& Wilcon, 2007; Klucken, Kagerer, Schweckendiek, Tabbert, Vaitl, \& Stark, 2009; Lascelles \& Davey, 2006; Lipp \& Purkis, 2005; Lovibond \& Shanks, 2002; Pleyers, Corneille, Luminet, \& Yzerbyt, 2007; Stahl \& Unkelbach, 2009; Stahl, Unkelbach, \& Corneille, 2009; Wardle, Mitchell, \& Lovibond, 2007). As a whole, the current evidence suggests that EC is based on propositional rather than associative processes (see De Houwer, 2009; Mitchell, De Houwer \& Lovibond, 2009), which in turn has important implications for current conceptualizations of attitudes formation.

Recently, however, Ruys and Stapel (2009) argued that contingency awareness is not necessary for EC of high-novelty CSs. In order to address this possibility, these authors conditioned Chinese kanjis and geometric figures (i.e., high-novelty CSs) with positive and negative USs. Participants then rated the positivity of the CSs and completed a memory task in which CSs had to be related to the US picture with which they had been paired (i.e., identity awareness memory task). The evaluative ratings confirmed the successful conditioning of the CSs, independently of whether these CSs could be related to their US in the memory task. The latter finding suggests that EC may arise as the result of the automatic 
formation of associations, at least for CSs that are not associated with prior evaluative knowledge in people. In this context, one important question is whether EC of high-novelty stimuli is also impervious to attentional resources.

Importantly, Pleyers, Corneille, Yzerbyt \& Luminet (2009) noted that the emergence of conflicting findings from past EC studies that manipulated attentional resources (Field \& Moore, 2005; Fulcher \& Hammerl, 2001; Walther, 2002) could be due to methodological limitations inherent to these studies. These authors re-examined the role of attentional resources in EC using a stronger design and found both contingency awareness and EC to be reduced among participants engaged in a concurrent auditory 2-back task. Because this study made use of low-novelty CSs (i.e., everyday consumption products), it remains to be examined whether attentional resources play a role in EC for high-novelty stimuli as well.

The latter question was addressed here by conditioning the high-novelty CSs used by Ruys and Stapel (2009) in control participants versus participants engaged in a concurrent auditory 2-back task. Obtaining evidence that EC of high-novelty stimuli is independent from contingency awareness and attentional resources would provide strong support in favor of the associative view. In contrast, finding that EC of high-novelty stimuli depends on resources should invite caution when concluding that EC of high-novelty stimuli is based on an automatic form of associative learning.

\section{Method}

\section{Participants and design}

Sixty-one French-speaking participants (32 women; mean age $=21.95 ; S D=2.89$ ) took part in the experiment. The design was a 2 (Load: Low-Load versus High-Load) by 2 (CS type: CS associated with a positive US versus a negative US; in short: CS+ versus $\mathrm{CS}-$ ) mixed design. The Load factor varied between participants and the CS type factor varied within them. Participants recruited on the university campus received $5 €$ for their participation 
in three experiments (the present study was completed after a short unrelated study concerned with face processing).

\section{Conditioning Materials}

Conditioning materials were borrowed from Ruys and Stapel (2009). CSs were eight high-novelty stimuli of neutral valence (two polygons and six Chinese kanjis). USs were four positive (balloons 8162, flowers 5010, mountains 8190, and a summer lake 5760) and four negative (dirty dishes 9390, skulls 9440, cigarette buds 9830, and a car wreck 9911) IAPS pictures.

\section{Procedure}

The general procedure of the experiment was similar to Ruys et al.'s (2009), except for the manipulation of the Load factor, which was similar to that used by Pleyers et al. (2009). All participants were first asked to wear headphones. Participants in the Low-Load condition were informed that music would be played in the headphones. Participants in the High-Load condition were informed that they would hear numbers and that their task would be to press the spacebar each time they would hear a number identical to the one they heard two places before (auditory 2-back task). Participants in both conditions were then instructed to pay attention to stimuli that would be appearing on the computer screen. They were told that the presentation of the stimuli would be followed by several questions about these stimuli.

The conditioning phase then started, with music or numbers played in the headphones depending on condition. All participants were exposed to eight CS-US associations displayed on a computer screen. CS pictures were superimposed at the bottom of positive or negative US pictures that filled the entire screen. Each CS-US association was presented seven times for one second, resulting in a total of 56 presentations. Associations were presented in a random order and followed by a blank screen for $1.5 \mathrm{~s}$. 
Following the conditioning phase, participants removed their headphones and started the evaluation phase. Participants were asked to report their global feelings toward the CS on a 9-point scale ranging from 1 (very negative feelings) to 9 (very positive feelings). The last phase of the experiment was a memory test. Each CS was presented along with the eight US pictures. Participants' task was to relate each CS with one of the eight USs. Participants could respond "I don't know" if they had no recollection of the pairing ${ }^{2}$. CS order was randomized in the evaluative and memory tasks. Finally, participants were debriefed, thanked, paid, and dismissed.

In short, the main differences between the experiments of Ruys \& Stappel (2009) were (1) participants in the present study only saw meaningless stimuli, (2) that all of them wore headphones, and (3) that half of them were engaged in a secondary 2-back task.

\section{Results}

\section{Check of the load manipulation}

We tested the effectiveness of our load manipulation by examining its impact on participants' encoding of the CS-US associations. Because of the mixed nature of our design, we analyzed participants' contingency awareness for the CSs by means of multilevel modeling ${ }^{3}$. First, each CS was categorized as "contingency aware" if it had been correctly related to its respective US picture in the memory task and as "contingency unaware" otherwise. These eight contingency scores per participant were then submitted to a multilevel analysis (SAS PROC MIXED) using valence (negative $=-1$ and positive $=+1$ ) as the level-1 factor and load (low load $=-1$ and high-load $=+1$ ) as the level-2 factor. Confirming the success of our load manipulation, only the load main effect was significant, $F(1,59)=28.73$, $p<.001$. The overall number of contingency aware items was $2.16(S D=2.54)$ out of a maximum of eight, and participants correctly reported a higher number of CS-US associations in the low-load $(M=3.58, S D=2.84)$ than in the high-load $(M=.70, S D=.79)$ condition. 
EC effect

Participants' eight CS evaluations were submitted to a multilevel analysis (SAS PROC MIXED) using valence (negative $=-1$ and positive $=+1$ ) as the level- 1 factor and load (low load $=-1$ and high-load $=+1$ ) as the level-2 factor. The valence main effect was significant, $b=0.34, F(1,425)=11.43, p<.001$, with more positive ratings of CSs + than CSs-. More importantly, the valence by load interaction was significant, $F(1,425)=15.64, p<.0001$. Examination of the simple effects revealed similar ratings of CSs+ and CSs- when load was high, $b=-0.06, F(1,425)=0.16, n s$., but more positive ratings of CSs+ than CSs- when load was low, $b=0.75, F(1,425)=27.35, p<.0001$ (for means and SDs, see Figure 1).

\section{Role of contingency in the emergence of EC}

We examined the role of contingency awareness in the link between load and evaluative conditioning. To examine this multilevel mediational model, we submitted the eight CS evaluations to a multilevel analysis (SAS PROC MIXED) using valence (negative = -1 and positive $=+1$ ) as the level-1 factor and load (low load $=-1$ and high-load $=+1$ ) as the level-2 factor and adjusting for level-1 contingency awareness as well as for the interaction between valence and contingency awareness (Muller, Yzerbyt \& Judd, 2008; Yzerbyt, Muller \& Judd, 2004).

As before, the valence main effect was significant, $b=0.64, F(1,423)=31.15, p<.0001$, with more positive ratings of CSs + than CSs-. Of note, whereas the valence by load manipulation was no longer significant, $F(1,423)=2.66, p>.10$, the valence by awareness interaction proved highly significant, $F(1,423)=26.06, p<.0001$. Further probing this interaction confirmed similar ratings of CSs+ and CSs- when there was no awareness, $b=0.01$, $F(1,423)=0.00, n s$., whereas CSs+ were rated more positively than CSs- when there was awareness, $b=1.27, F(1,423)=37.86, p<.0001$ (for means and SDs, see Figure 2).

\section{Discussion}


EC of high-novelty stimuli proved sensitive to attentional resources: participants were less likely to correctly encode the CS-US pairings and were less likely to be conditioned when their attentional resources were otherwise taxed. Because the load manipulation was strictly similar to that used by Pleyers et al. (2009), it is unreasonable to argue that the load effect simply reflects participants' visual avoidance of the computer screen in the High-Load condition: participants were instructed to carefully monitor the information displayed on the screen and the concurrent task involved a sensory channel (auditory) that was different from that used for conditioning (visual). It is much more sensible to assume that EC of both lownovelty (Pleyers et al., 2009) and high-novelty (the present study) stimuli requires a successful encoding of the CS-US pairings, and that the latter encoding is resource-dependent. The mediation obtained here is fully consistent with this view.

One possibility is that the Load manipulation primed a non-evaluative mindset in participants. For instance, Gast \& Rothermund (2010) recently showed that EC is observed when participants are involved in an evaluative task but not when they have to judge evaluatively-irrelevant information about the CS-US pairings (e.g. geographic localization or age). In the present research, the 2-back task may have distracted Ps from the evaluative meaning of the stimuli, thereby reducing EC effects. Of note, this alternative account of our findings would also support the view that EC of high-novelty stimuli is not based on purely automatic associative processes (as it would then depend on processing goals; see also Corneille et al., 2009). But, even more importantly, given the strong impact of our load manipulation on contingency-awareness, it seems logical to assume that our 2-back task manipulation did affect our participants' attentional resources, not just their mindset.

Regarding the role of identity awareness, the present data sharply differ from those obtained by Ruys and Stapel (2009). We can only speculate about why Ruys and Stapel (2009)'s findings did not prove more robust. But, in any case, this is only a secondary issue. 
Stahl and Unkelbach (2009) and Stahl, Unkelbach and Corneille (2009) have recently shown that awareness of US valence, rather than awareness of US identity, is critical to EC.

Encoding US identity implies encoding its valence, but encoding US identity does not contribute to EC effects over and above mere encoding of US valence. Hence, measures of valence awareness should generally be favored because they are sufficient and more sensitive than identity awareness measures. Nevertheless, the identity awareness measure used here was sensitive enough to reveal its role as a mediator of the load effect on EC. Of importance too, Stahl and colleagues showed that valence awareness is involved in EC of both lownovelty and high-novelty (i.e., meaningless letter strings) stimuli.

In sum, the present evidence adds to the available literature suggesting that no EC is observed without contingency awareness and that EC depends on resources, for both lownovelty and high-novelty CSs. In light of this work, and given that EC is generally considered to be the best case for an automatic form of associative learning, it seems premature (and not quite parsimonious) to argue that attitudes may be formed through dual processes, even for attitude objects for which there is little prior evaluative knowledge. This is of course not to say that only one evaluative learning process (i.e. propositional) underlies attitudes formation. As a matter of fact, it is hardly possible to provide evidence for the non-existence of a secondary (i.e., associative) form of evaluative learning. Rather, our message is that researchers who claim that two evaluative learning processes (i.e., a propositional process and an associative one) contribute to the formation of attitudes should be expected to provide more compelling evidence for the existence of the second process. 


\section{Footnotes:}

1. Although associative processes should not necessarily be considered automatic (e.g., Pacton \& Perruchet, 2008), associative processes are generally thought to be independent of cognitive resources and to occur in the absence of awareness in social cognition research (e.g., Gawronski \& Bodenhausen, 2006).

2. Prior to the US identification task, participants were also asked to recall the valence of the US associated with each of the eight CS. However, these data are difficult to interpret due to the omission of a "Don't know" option (see Stahl, Unkelbach \& Corneille, 2009) and so will not be further discussed.

3. Not surprisingly, similar results emerged when the data were analyzed by means of a mixed-model ANOVA. In particular: (1) EC and contingency awareness were reduced under Load, (2) EC was found on contingency-aware CSs, and (3) EC was not found on contingency-unaware CSs. 


\section{References}

Corneille, O., Yzerbyt, V. Y., Pleyers, G., \& Mussweiler, T. (2009). Beyond awareness and resources: Evaluative conditioning may be sensitive to processing goals. Journal of Experimental Social Psychology, 45, 279-282.

Dawson, M. E., Rissling, A. J., Schell, A. M., \& Wilco, R. (2007). Under what conditions can human affective conditioning occur without contingency awareness? Test of the evaluative conditioning paradigm. Emotion, 7, 755-766.

De Houwer, J. (2009). The propositional approach to associative learning as an alternative for association formation models. Learning \& Behavior, 37, 1-20

Field, A. P., \& Moore, A. C. (2005). Dissociating the effects of attention and contingency awareness on evaluative conditioning effects in the visual paradigm. Cognition \& Emotion, 19, 217-243.

Fulcher, E. P., \& Hammerl, M. (2001). When all is revealed: A dissociation between evaluative learning and contingency awareness. Consciousness and Cognition, 10, $524-549$.

Gast, A. \& Rothermund, K. (2010) What you see is what will change: Evaluative conditioning effects depend on a focus on valence.

Gawronski, B., \& Bodenhausen, G. V. (2006). Associative and propositional processes in evaluation: An integrative review of implicit and explicit attitude change. Psychological Bulletin, 132, 692-731.

Klucken, T. Kagerer, S. ; Schweckendiek, J. ; Tabbert, K. ; Vaitl, D. \& Stark, R. 2009. Neural Electrodermal and behavioral response patterns in contigency aware and unaware subjects during a picture-picture conditioning paradigm. Neuroscience. 158, 721-731 
Lascelles, K. R. R., Davey, G. C. L. 2006. Successful differential evaluative conditioning using simultaneous and trace conditioning procedures in the picture-picture paradigm. The Quarterly Journal of Experimental Psychology, 59 (3), 482-492.

Lipp, O. V., \& Purkis, H. M. (2005). No support for dual process accounts of human affective learning in simple Pavlovian conditioning. Cognition and Emotion, 19, 269-282.

Lovibond, P. F., \& Shanks, D. R. (2002). The role of awareness in Pavlovian conditioning: Empirical evidence and theoretical implications. Journal of Experimental Psychology: Animal Behavior Processes, 28, 3-26.

Mitchell, C. J., De Houwer, J., \& Lovibond, P. F. (2009). The propositional nature of human associative learning. Behavioral and Brain Sciences, 32, 183-198.

Muller, D., Yzerbyt V. Y., Judd, C. M. (2008). Adjusting for a mediator in models with two crossed treatment variables. Organizational Research and Methods, 11, 224-240.

Pleyers, G., Corneille, O., Luminet, O., \& Yzerbyt, V. (2007). Aware and (Dis)liking: Itembased analyses reveal that valence acquisition via evaluative conditioning emerges only when there is contingency awareness. Journal of Experimental Psychology: Learning, Memory, and Cognition, 33, 130-144.

Pleyers, G., Corneille, O., Yzerbyt, V. Y., \& Luminet, O. (2009). Evaluative conditioning may incur attentional costs. Journal of Experimental Psychology: Animal Behavior Processes, 35, 279-285.

Ruys, K. I., \& Stapel, D. A. 2009. Learning to like or dislike by association: no need for contingency awareness. Journal of Experimental Social Psychology, 45, 1277-1280.

Rydell, R. J., McConnell, A. R., Mackie, D. M., \& Strain, L. M. (2006). Of two minds: Forming and changing valence inconsistent implicit and explicit attitudes. Psychological Science, 17, 954-958. 
Stahl, C., \& Unkelbach, C. (2009). Evaluative learning with single versus multiple USs: The role of contingency awareness. Journal of Experimental Psychology: Animal Behavior Processes, 35, 286-291.

Stahl, C., Unkelbach, C. \& Corneille, O. (2009). On the respective contributions of awareness of US valence and US identity in attitude formation through evaluative conditioning. Journal of Personality and Social Psychology, 97, 404-420.

Walther, E. (2002). Guilty by mere association: EC and the spreading attitude effect. Journal of Personality and Social Psychology, 82, 919-934.

Wardle, S., Mitchell, C., \& Lovibond, P. (2007). Flavor evaluative conditioning and contingency awareness. Learning \& Behavior, 35, 233-241.

Yzerbyt, V. Y., Muller, D., \& Judd, C. M. (2004). Adjusting researchers' approach to adjustment: On the use of covariates when testing interactions. Journal of Experimental Social Psychology, 40, 423-431. 
Fig. 1. Mean evaluation (and standard deviations) of the CSs as a function of CS type and Load.

Fig 2. Mean evaluation (and standard deviations) of the CSs as a function of CS type, Load and Contingency-awareness. 


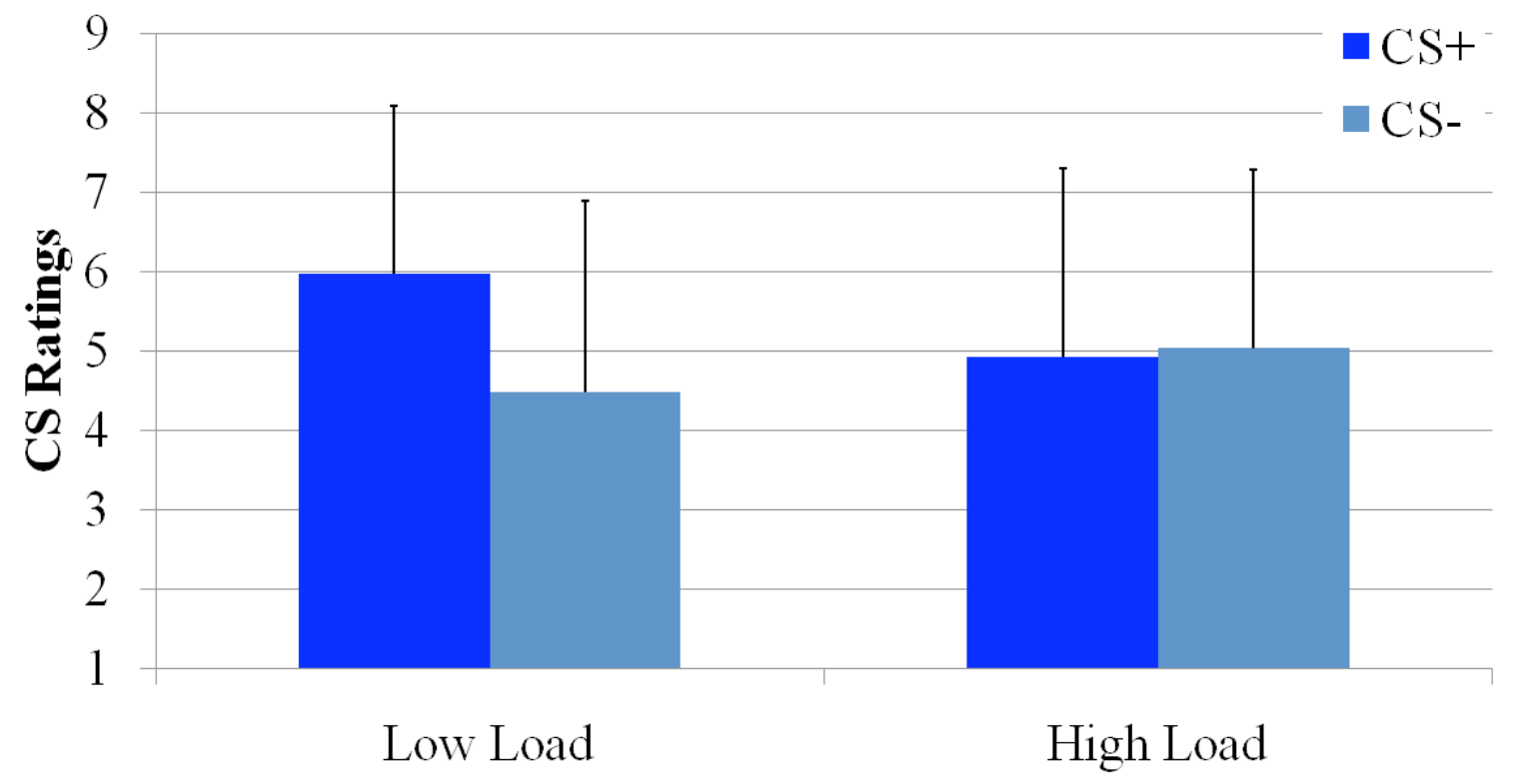




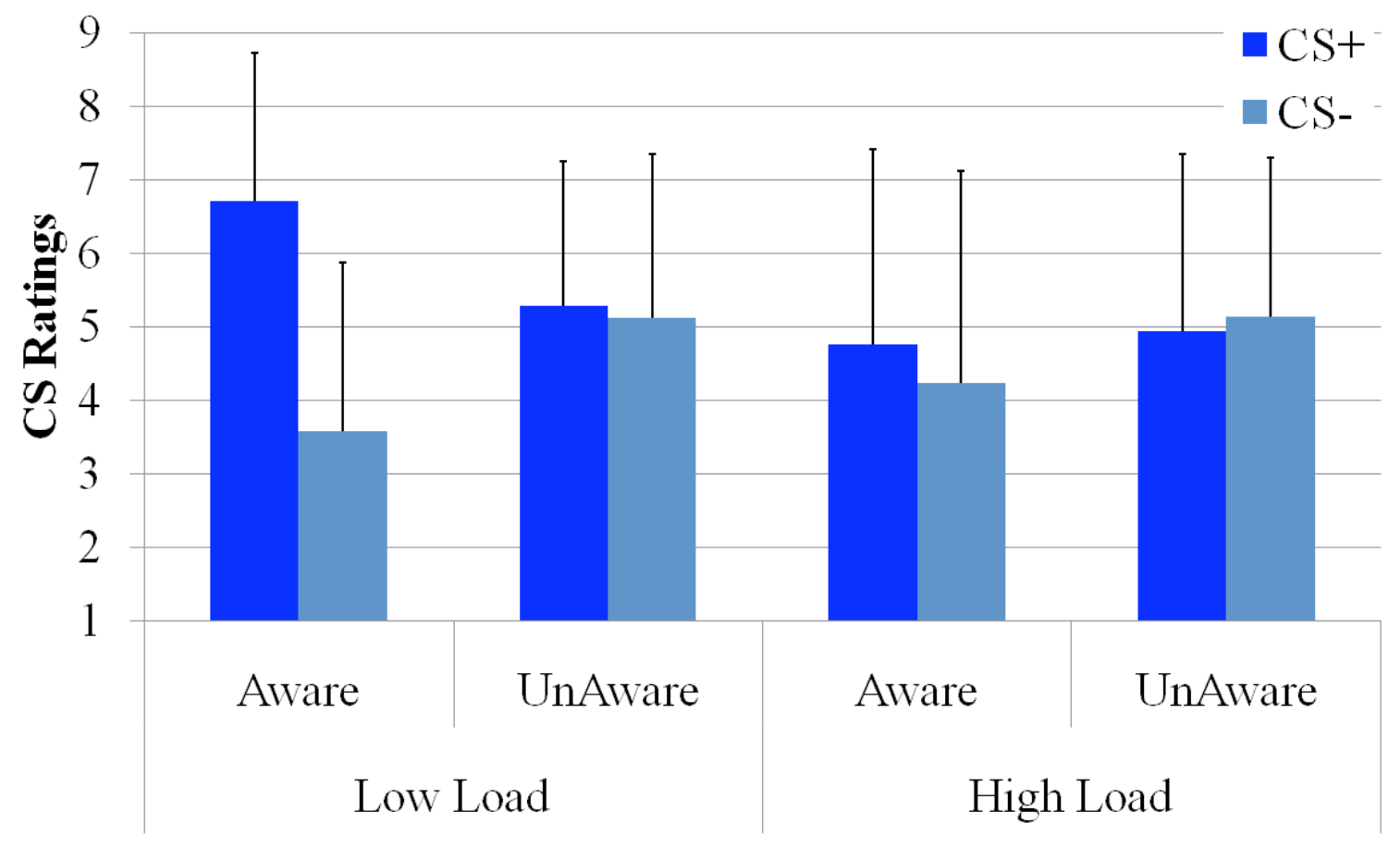

